This item was submitted to Loughborough's Research Repository by the author.

Items in Figshare are protected by copyright, with all rights reserved, unless otherwise indicated.

\title{
Understanding the student perspective of Microsoft OneNote as a learning resource in higher education
}

PLEASE CITE THE PUBLISHED VERSION

https://doi.org/10.21125/iceri.2019.2404

PUBLISHER

IATED Academy

VERSION

AM (Accepted Manuscript)

\section{PUBLISHER STATEMENT}

This paper: S. Bamforth, G. Perkin, J. Flint (2019) UNDERSTANDING THE STUDENT PERSPECTIVE OF MICROSOFT ONENOTE AS A LEARNING RESOURCE IN HIGHER EDUCATION, ICERI2019 Proceedings, pp. 9838-9847, appears here with the permission of the publisher.

\section{LICENCE}

CC BY-NC-ND 4.0

\section{REPOSITORY RECORD}

Bamforth, Sarah, Glynis Perkin, and James Flint. 2019. "Understanding the Student Perspective of Microsoft Onenote as a Learning Resource in Higher Education”. Loughborough University. https://hdl.handle.net/2134/14916429.v1. 


\title{
UNDERSTANDING THE STUDENT PERSPECTIVE OF MICROSOFT ONENOTE AS A LEARNING RESOURCE IN HIGHER EDUCATION
}

\author{
Sarah Bamforth1, Glynis Perkin², James Flint ${ }^{3}$ \\ 1,2,3 Loughborough University (United Kingdom)
}

\begin{abstract}
Microsoft OneNote is a digital notebook where notes can be created, stored, organised and shared. OneNote is used in industry but is also marketed to the education sector, however, there is little published to date about the application of OneNote to learning in Higher Education. This paper discusses how OneNote has been trialled on three modules with Part A and B Electrical Engineering Students at a UK university, in the School of Mechanical, Electrical and Manufacturing Engineering. The paper also shares the findings of a study to explore the student perspective of Microsoft OneNote as a learning resource, against the context of the University's Virtual Learning Environment. The research was undertaken by staff at the University's Centre for Academic Practice on behalf of the School. The study surveyed the literature to understand how OneNote is being used within education and employed both online survey and focus group methods with students. Although a small study, the use of multiple research methods enabled the triangulation of data, giving greater confidence in the findings of the study. The results include the finding that there is a difference between how Part $A$ and Part B students value the capabilities offered by OneNote. With Part B students reporting greater appreciation of the collaboration features of the tool. The results also challenge assumptions that students are able to buy the most appropriate technology tools to interact with OneNote.
\end{abstract}

Keywords: Learning Technology

\section{INTRODUCTION}

OneNote offers a different learning experience to traditional Virtual Learning Environments (VLEs) and more intimate links with personal IT technologies such as mobiles and tablets. Adopting OneNote in education offers the possibility to interact with students in a much more seamless way across a range of digital platforms. It offers an alternative experience to traditional VLEs, which is 'on demand' whereas OneNote can 'push' content. There is also the possibility to work collaboratively using the sharing facilities in OneNote, where students and staff can all write on one page. It has the potential to be useful for group projects or as a portfolio tool for final year projects. However, the framework for learning is not yet well defined. OneNote is very flexible but it is relatively unstructured and needs teaching and learning knowledge to design the content if it is to be effectively applied in higher education (HE). Yet the impact of using Microsoft OneNote in a university teaching context does not appear to be well documented in the literature.

A study was undertaken at Loughborough University to explore, from the students' perspective, the application of OneNote as a learning resource. In addition to students being able to access lecture notes on the VLE, OneNote was piloted as the main learning resource by one lecturer on three modules with conventionally taught lectures, one in Part A ( $1^{\text {st }}$ Year $)$ and two in Part B ( $2^{\text {nd }}$ Year $)$. In addition to annotated lecture notes being made available in OneNote, the collaborative space was used to set questions where the class could all respond.

This paper presents the findings of a small study undertaken at a UK University with Part A and B Electrical Engineering students to understand, from the student perspective, how students interact with Microsoft OneNote, their perceptions of it as a learning resource and any obstacles or aids to its use.

\section{BACKGROUND}

\subsubsection{An Overview of Microsoft OneNote}

Microsoft Office give an online explanation of OneNote 2010 [1] as:

"a digital notebook that provides a single place where you can gather all of your notes and information, with the added benefits of powerful search capabilities to find what you are looking for 
quickly, plus easy-to-use shared notebooks so you can manage information overload and work together with others more effectively."

The University of Leicester [2], in an IT Help web page, explains that OneNote also provides facility for users to gather and organise text, images, links, screen shots and recordings. They also show how a lecturer could create a notebook for a module and then have distinct sections for each lecture which they can then share with their students.

There is a wealth of available functionality described by Jeschke and Knipping et al., [3], for example, OneNote integrates with other office applications, notes may be archived in several ways such as by tagging or sorting, if using devices such as tablets it is possible to add handwritten notes to pages. Content from web pages may be dragged and dropped into a OneNote notebook page and lecturers can share material with students and students may pose questions or provide answers to questions to their lecturer.

It is possible to use OneNote to undertake arithmetic, it can also be used to perform more advanced mathematics and users can build their own equations [4].

\subsubsection{Why consider OneNote for Higher Education?}

Almost anecdotally, Turner [5] points out that OneNote appears to be more accessible than other similar programmes, which is probably due to it being part of the Microsoft Office package. This is also mentioned by Jeschke and Knipping et al., [3] who write 'The use of OneNote ...is based on the fundamental assumption that nearly everyone knows how to use office applications'.

However, Guerrero and Dujardin et al. [6], have undertaken a technical comparison of six electronic laboratory notebooks, which included OneNote, from the technical comparison two electronic notebooks were chosen. These were PerkinElmer Elements and Microsoft OneNote. These two were evaluated by 28 scientists over a 3-month period and by 80 students undertaking hands-on practical exercises. Five parameters were evaluated, namely, flexibility, collaboration, ease of searching, image editing and accessibility. All of the 28 scientists and $69 \%$ of the 80 students preferred OneNote. Tofan [7] points out that 'Other technologies can achieve similar results, but none offers all the features of OneNote.'

There is an abundance of literature that details how to use OneNote. Some of these are very detailed and include screenshots depicting different tasks, for example, [2] and [1]. Jeschke and Knipping et al. [3], write that 'it is easy to use after a short training period'.

\subsubsection{How other institutions are using OneNote and student opinions}

Falconer and Nicodemus et al., [8] explain how they have produced a 'course package' for thermodynamics using OneNote; it is also designed to be used, with students voting, in a flipped classroom setting. The focus of the course package is described as integrating active-learning methods into the course'.

OneNote has also been used with pupils in secondary schools, in one example pupils were provided with laptops and used OneNote to organise their work electronically. It was felt that traditional teaching and assessment often puts students in competition with each other rather than being a collaborative exercise. Teachers believed that the work of pupils using OneNote and other forms of IT had improved when compared to that of pupils who had not been involved in the research project. It is also mentioned that OneNote provided a 'richer learning experience' [9].

At the University of Alaska, tablet PCs using OneNote were utilised in place of a traditional blackboard, this was found to have a number of benefits, for example, being able to re-display earlier work that would have been erased from a blackboard, removes the blocking of the blackboard when writing material and digital ink can be saved and revisited. Student responses to the use of OneNote were sought and it was found that their reaction was positive [10].

Jeschke and Knipping et al., [3] used OneNote with 16 students and their preliminary findings determined that students found OneNote lectures to be captivating. However, Evangelinos [11] investigated the use of OneNote and the perceptions of five students, he has also produced 'step-bystep instructions which may be requested from the author. The students were mostly positive and found OneNote easy to use but some concerns were raised relating to copyright, intellectual property and use of multimedia. One student preferred to use paper saying that 'it better matched their physical workflow'. 
An American institution introduced total digital delivery of an engineering module using OneNote as it was found to be a very flexible programme. The material is available prior to the lecture, after the lecture the annotated and completed set of notes are made available to the cohort through the website [12].

Turner [5] used OneNote with 20 students to facilitate the learning of English academic vocabulary by non-native English language speakers. Students had mixed views regarding the use of OneNote, for example, one student preferred to learn by using pen and paper and another found studying by using a laptop to be difficult. Favourable comments included mention of the fact that the material wouldn't get lost and ease of making changes.

\subsubsection{Pedagogy and Learning}

According to Jeschke and Knipping et al. [3], using OneNote is a form of blended learning that combines traditional lectures with new media, bringing together theories of constructivism, behaviourism and cognitivism, which in turn supports learner diversity. There are also well evidenced benefits associated with collaborative study compared to individual study, for example, [13] and [14].

There is, however, conflicting evidence to consider; it is well documented that learners have greater retention in their memory when they have hand written lecture notes or other information as opposed to when they have typed material into a computer [15], [16], [17]. However, there does not appear to be any large-scale rigorous research into the effects on learning of writing on a tablet versus writing on paper.

\section{METHODOLOGY}

This paper reports the findings of a study undertaken by the Centre for Academic Practice on behalf of the School. The study aimed to understand:

1. How students are accessing OneNote (technology)

2. How students report using OneNote (to do what)

3. What is influencing how students are choosing to access and use content on OneNote

4. The student perception of the advantages and disadvantages of OneNote (as juxtaposed with the VLE)

As part of the study an online questionnaire survey and two focus groups were conducted with Part A and B Electrical Engineering students. The online questionnaire method enabled the study to sample quickly those students who had undertaken one or more of the modules where OneNote was trialled. Focus groups were used to explore in more depth the issues identified in the questionnaire survey in order to produce rich data [18]. Multiple methods were used within the small study to enable the triangulation of data, giving more confidence to the findings of the study.

Students were invited to participate in the online questionnaire survey, via email invitations sent through the University's VLE. Invitations were sent to students who were registered on the three, previous year's, Electrical Engineering Modules where Microsoft OneNote was trialled. All three modules were led by the same member of academic staff.

Approximately 154 students were invited to participate in the online survey, with a response rate of $7 \%$. Focus group participants were invited in a similar manner, with 13 students participating across two focus groups. The first comprised Part A students $(n=3)$ and the second Part $B$ students $(n=10)$. The focus groups were organized in this way in order to identify any potential differences in perceptions between the two year groups.

\section{RESULTS}

\subsection{Survey Results}

Half of the survey respondents answered the questions about which technology they used to access OneNote. Fig. 1 shows the different devices used by students $(n=5)$. Of the students responding to this question, the majority used more than one device. Only one respondent used a single device, which was a computer. Fig. 2 shows how each device is being used by students to interact with 
OneNote. This shows that mobile phones are only used to view content. Greater interaction is only undertaken with computers, tablets and tablet PCs. When asked to explain why a device was their preferred way of interacting with OneNote, their responses suggested that for those with access to a tablet PC they valued portability and the stylus for easier writing. For those who used a computer they valued the screen size and ease of navigation. No respondent reported that they preferred to use a mobile phone to access content. All respondents $(n=10)$ to the survey indicated that they used OneNote in some way. Fig. 3 shows that $90 \%$ of responding students used OneNote to read material. $40 \%$ of students made their own notes on OneNote, and $30 \%$ used the collaboration feature.

Fig. 4 shows what the provision of resources on OneNote means to the students. Centralised storage of notes and annotating electron lecture notes were the most prevalent responses. Free text responses further explain this. Interestingly, two respondents identified that they continued to use pen and paper.

"Having everying on [VLE] is good, however, it's far more convenient to have everything in one place and be able to interact with during lectures and tutorials themselves."

"The convenience of having all your modules materials in one, easily accessible place is great for students."

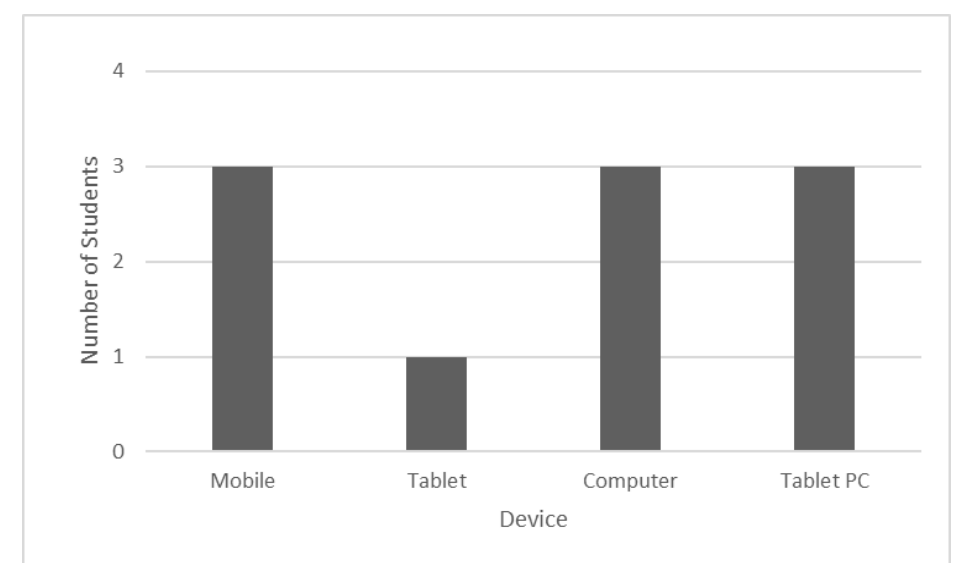

Figure 1: Devices used by students to access OneNote $(n=5)$

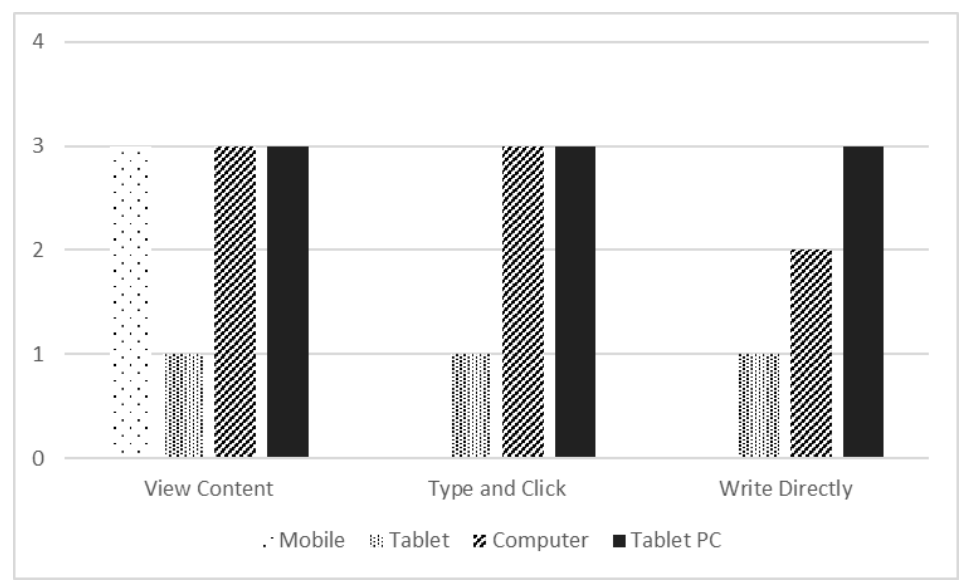

Figure 2: How content is interacted with by device $(n=5)$ 


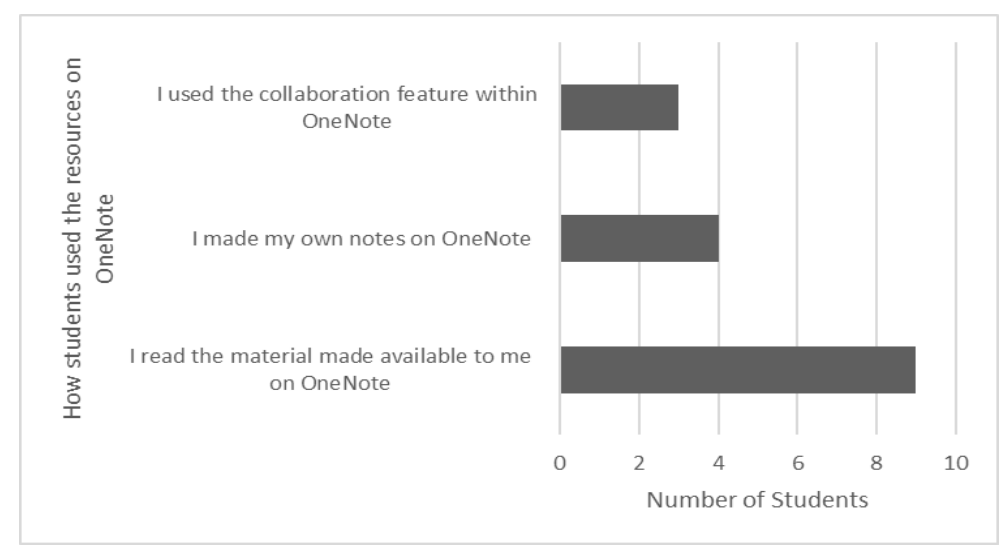

Figure 3: How students report using OneNote $(n=10)$

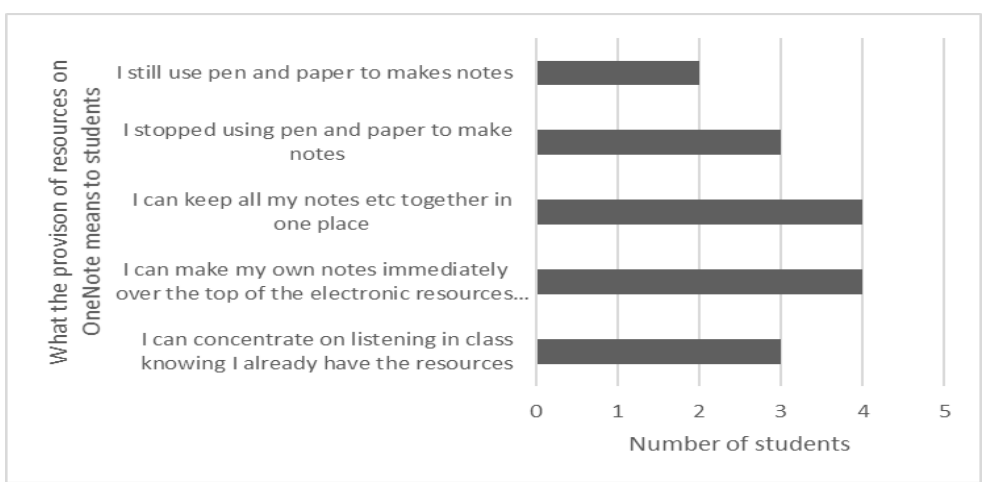

Figure 4: What the provision of resources on OneNote means to students $(n=5)$

When asked if they believed that the use of OneNote had any impact on their learning $(n=10) 50 \%$ responded that it had helped them learn the subject a bit, $40 \%$ that it had helped them a lot to learn the subject. One person identified that it had significanlty hindered them learning the subject (this person preferred hand written notes and to download printable PDF files). Not all, but some of the students who felt that OneNote had helped them a lot, had only used the tool to view content, this suggests that it is not just the higher order interactions (adding to the notes within OneNote) that are associated with this belief.

\subsection{Focus Group Results}

\subsubsection{The student perception of OneNote (as juxtaposed with the VLE)}

Table 1 shows the advantages and disadvantages of OneNote as identified by the students through the focus group discussion. The findings have been separated to highlight any differences in perceptions between Part A and Part B students.

Table 1: Student Perception of the Advantages and Disadvantages of OneNote

\begin{tabular}{l|c|c}
\hline \hline Part A & ADVANTAGES & DISADVANTAGES \\
\hline & $\begin{array}{c}\text { Central areas where all documents are } \\
\text { stored. OneNote is more coherent [than } \\
\text { the university VLE] }\end{array}$ & $\begin{array}{c}\text { Technical issues with software - particularly } \\
\text { with relation to the desk space }\end{array}$ \\
\hline & $\begin{array}{c}\text { Compatibility issues with older mobile } \\
\text { phones } \\
\text { use the VLE means going to the website, } \\
\text { logging in and downloading all the PDFs }\end{array}$ & $\begin{array}{c}\text { Web access for OneNote glitches if internet } \\
\text { is not strong }\end{array}$ \\
\hline \hline & Captures the annotations on diagrams & $\begin{array}{c}\text { Still have to use the VLE for submitting } \\
\text { coursework. }\end{array}$ \\
\hline
\end{tabular}




\begin{tabular}{|c|c|c|}
\hline & & $\begin{array}{l}\text { Stylus written annotations on slides difficult } \\
\text { to read. }\end{array}$ \\
\hline \multirow[t]{10}{*}{ Part B } & Ease to use & Email addresses do not always work \\
\hline & $\begin{array}{c}\text { Well structured - } \\
\text { All the notes in one place } \\
\text { Chronological } \\
\text { Easier to navigate than university VLE }\end{array}$ & $\begin{array}{l}\text { It's not universally used - not all lecturers } \\
\text { use it }\end{array}$ \\
\hline & Easy accessibility & Printing from OneNote \\
\hline & Modern & $\begin{array}{l}\text { Students might be scared of using the } \\
\text { collaboration space }\end{array}$ \\
\hline & Interactive & Need to go through email to access \\
\hline & $\begin{array}{l}\text { Collaboration space. - easy to collaborate } \\
\text { on OneNote on other modules }\end{array}$ & $\begin{array}{l}\text { You need the 'right' technology to use it in } \\
\text { lectures e.g. a tablet }\end{array}$ \\
\hline & $\begin{array}{c}\text { Organised notes (but depends on } \\
\text { lecturer's organisation }\end{array}$ & $\begin{array}{c}\text { Clunky - sometimes lecture [notes] are split } \\
\text { without warning }\end{array}$ \\
\hline & Search option & Full screen writing/reading is hard to find \\
\hline & Digital storage of notes & $\begin{array}{c}\text { Writing revision notes, have to flick back and } \\
\text { forth to see lecture notes }\end{array}$ \\
\hline & Upload time, lets you follow in the lecture & Past papers and lecture recording on VLE \\
\hline
\end{tabular}

Additionally, four key themes emerged from the discussions. Some of these were directly related to OneNote, others to the wider context of technology in education.

\section{Hardware}

A key theme that emerged from the focus group discussion was that of students having access to the right technology to get the most out of OneNote.

"You need to have the right technology to use it like a tablet with the 'write on it' technology." (Part B)

"Tablet is the best option, but it's one more thing to take care of, but these devices are expensive... Most students are on student loans." (Part A)

"OneNote is difficult for students who don't have devices with the latest technology so I couldn't download OneNote on my phone [iPhone 5])." (Part A)

Only 3 of the 10 Part B focus group students had access to a stylus. For students who wanted to make notes within OneNote, there was a desire to have access to a stylus to precipitate handwritten electronic notes.

"If a stylus offered the same flexibility as paper, then there's no reason not to use it l'd use it paper is natural to write on... if I had an iPad or something, l'd prefer it to paper. "(Part B)

"if I had access to a stylus, l'd annotate the slides a lot more." (Part B)

The findings of the questionnaire survey suggested that students were only using mobile phones to view content. The focus group discussion offered greater insight into this behaviour, citing factors such as difficulty reading notes on the phone.

"It's OK if you're on a bus and just want to flick through." (Part B)

"I usually write notes on paper, but you get a bit lost with what you've got on paper and what he's got on slides, l'd rather write alongside his because you can't do it on a phone in class." (Part B)

\section{Software}

Issues with the software interfered with students' user experience. For example, students who preferred to work with and annotate paper notes found that printing from OneNote was much more cumbersome than from the VLE. 
"Printing issues from OneNote - printing slides, you need to take slides and put in Word. I want to print out." (Part B)

"I want to print lecture notes but there's a problem with the printing format, bits are missing. I want paper notes. I want to write my own notes." (Part A)

Students also reported issues with the interface. Both that the interface varied across different devices and that there were issues on some devices in getting the page they wanted to read centred and full screen.

"The interface isn't consistent across all devices from one computer to another to a tablet to phone, they all work in different ways." (Part B)

"Sometimes getting it into full swing reading mode is difficult...I used an iPad, it's a Microsoft problem, I just prefer Google." (Part B)

"Problems reading emails - only a bit of screen need to adjust settings every time you go into it." (Part B)

"It won't re-centre itself." (Part B)

"Zooming in is not right." (Part $B$ )

Whilst the discussion indicated that students felt that the app took up a lot of storage space on their phone, others liked how the system did not take up storage space on a computer, compared to downloading files from the VLE.

"Can download it into your computer and organise it into your own folders without using your storage." (Part B)

Students also liked the ability to search within the notes, which is not an option on the VLE.

\section{Content structure}

When discussing whether OneNote should be more widely used across the university, a key theme that emerged from the Part B group concerned how lecturers structure their notes. This issue of structure also resurfaced elsewhere in the discussions.

"Not all the lecturers have set it out nicely on [VLE], even if they haven't one thing l'll give [VLE] is everything is there but it's horrible to find it in some cases." (Part B)

"Most of the time he labels weeks and lecture 1, lecture 2. Sometimes he puts details in such as this document is about an oscillator, but l'd prefer him to use descriptive titles all the time." (Part B)

"Clunky - terms that sometimes the lecture is split into like two or three sheets without warning so you can put them into subfolders, but no lecture seems to use that." (Part B)

\section{Learning Space}

Physical desk space was also identified as an issue. The Part A students who liked to take paper notes, or who did not have access to a stylus reported that there was not sufficient space on the desk to use a paper notepad and a laptop. This issue was echoed by the Part B students, with them identifying that there was not enough desk space if the lecture was full.

"Not practical to bring a laptop." (Part A)

"Because the desks are quite small in the lecture it's quite cumbersome to bring a laptop in as there's not really any space so I could look at OneNote during the lecture wasn't an option." (Part A)

The practical issue of powering the technology to run OneNote also emerged from both focus group discussions.

"There are not enough sockets for charging." (Part A)

"Need more power sockets, if you have a low battery, you might as well leave." (Part B)

\subsubsection{Other issues}

\section{Paper}

A finding from the focus groups was that there were students in both of the discussions who wanted to use paper. Some wanted to use paper throughout the learning process, whilst others wanted to use it 
at a certain stage e.g. revision. In stark contrast were the students who valued the digital storage of OneNote. However, both the digital and paper students felt strongly that lecturers should not turn up to class with all of the notes printed out for them as they wanted to print only want they wanted. The students felt strongly about the waste of paper.

"Another module where l've got bunches of booklets, they're all go in the bin whereas with OneNote I'll be able to access all notes after l've finshed the module." (Part B)

"It's more likely for me to delete a photo [of an engineering equation] than tear a page out of my book, it'll stay in the book and I can refer back to it." (Part A)

Whilst the two focus group shared views on many of the themes that emerged from the discussion there were two areas where there was a strong difference in opinion between the Part A and Part B groups. These concerned collabortion and value of OneNote.

\section{Collaboration Feature}

The Part A students did not perceive there to be value in the collaboration space on OneNote. They felt there was no compulsion to interact with it.

"I personally wouldn't write anything on it because I just don't see any reason to do this." (Part A)

"There's about 80 people on the course, so why would you contribute to it?" (Part A)

"If you don't understand... and you've exhausted your friends, then you go to see the lecturer." (Part A)

"I only know of four people who do this [write on the collaboration space]." (Part A)

Similarly the Part B students expressed a reluctance to use the collaborate feature if they were stuck.

"Personally, I prefer to ask a mate first." (Part B)

"I don't want to look incompetent for everyone to see." (Part B)

However, Part B students did use and value this feature. Despite a fear of looking incompetent, they reported that what compelled them to use this feature was the need for answers.

"We had a limted set of answers given to us for the exam so everyone was just throwing out answers for what they thought the answer was." (Part B)

\section{Value of OneNote in a University Context}

The Part A students participating in the focus group, although identifying some advantages of OneNote, such as the ability to launch it from the desk top and annotated slides for revision, saw little value in OneNote, believing it to replicate the function of the VLE.

"the way that we use it [OneNote] is exactly the same as we use [VLE]." (Part A)

"I thought it was just a note taking app to be honest." (Part A)

Conversely, the Part $B$ focus group, although identifying disadvantages, the overriding consensus was that they wanted OneNote.

\section{Value of OneNote Beyond University}

The Part A focus group indicated that they did not feel that OneNote would be relevant outside of university and did not consider it to be a particularly useful digital skill.

"I don't think its greatly used. I might put it on my CV. Some companies might look for that" (Part A).

In stark contrast, the Part B students indicated that not only did they use OneNote on group work for other modules where the lecturer was not using OneNote but they spoke about its use outside of the university.

"Probably, it's a good way of getting material to everyone quickly." (Part B)

"Definitely [digital skills] - things change every day you need to keep up." (Part B)

\section{DISCUSSION}

The findings of the survey suggest that an even proportion of mobile phones, computers and tablet pc's were used to access OneNote content. The findings of the focus group suggest that access to 
technology (not being able to afford a tablet pc with a stylus) and the learning space (limited desk space) may be impacting how students interact with OneNote in lectures. These findings suggest that more students might interact with digital notes in class if they had access to a stylus.

As hinted at in the online questionnaire survey, there is a strand of students who prefer to learn using paper. Even with access to a stylus, some would still revert to paper for revision. These students were not against the use of OneNote but appeared to be frustrated by the difficulty of printing notes from OneNote as compared to the VLE.

The Part A students who participated in the focus groups appear to see little value in OneNote. They feel that it replicates the access to lecture notes which are already available to students through the VLE. They feel it has little value outside of university and are reluctant to use the collaboration feature. This is in contrast to the Part B students who made use of the collaboration feature and valued the advantages offered by this software. Although engagement with the collaboration feature was hesitant at first it was eventually driven by need. These outcomes maybe very strongly influenced by the way the lecturer uses OneNote.

Even those, identified in the survey as preferring handwritten notes felt that OneNote should be more widely used but the issue of how material content is structured by the lecturer within OneNote is an important factor.

\section{CONCLUSIONS}

This paper presents the findings of a small study. Although providing an insight into the area of OneNote as a learning resource, further research is needed to verify the wider applicability of the outcomes. The findings of the study indicate that access to technology and physical learning space influence how students interact with content. The study identified students who wanted to take digital notes in class but who did not have access to that technology (with cost being cited as the contributing factor). This is in stark contrast to the assumption that, with access to student loans, students are able to buy the right devices for learning at university.

Getting students to value the learning enabled by the collaboration feature appears to be linked to students using this space. For both Part A and B students a barrier to engagement was the desire to avoid looking stupid in front of their peers. Where students had the need (past examination questions for revision with no solution provided by the lecturer), then students engaged with and valued this feature. Within the focus groups, Part A students reported no such driver. It was only the Part B students who reported experiencing this. This finding suggests that careful thought needs to be given to designing activities within the collaboration space to encourage participation.

Whilst the study found some commonality between Part A and Part B students in how they valued OneNote, such as the central location of all the notes, the overriding perception of the Part A students was that it replicated functionality offered by the VLE without many of the other features, such as coursework submission. Whilst Part B too identified where OneNote could not replace the VLE (access to past papers and lecture recordings) they reported valuing OneNote in a way not shown by the Part A students. For these Part B students, the structure and the ability to interact with centralised live notes was what made OneNote a more valuable tool than the VLE. The successful structuring of content was largely identified as lecturer dependent and the suggestions students made within the focus group discussion for improvement (clarity of naming) supports the view articulated in the introduction that teaching and learning knowledge is needed to design the content if it is to be effectively applied in HE. OneNote is very flexible and the way academic staff manage it potentially has a big effect on the students' experience of it.

\section{REFERENCES}

[1] Microsoft Office. Basic tasks in OneNote 2010. Available at: https://support.office.com/enus/article/basic-tasks-in-onenote-2010-29a50122-eb92-4eaf-8a39ae5f01094ddc\#_toc254270329 [Accessed on 26th September 2019]

[2] University of Leicester (undated). IT Help OneNote. Available at: https://www2.le.ac.uk/offices/itservices/ithelp/my-computer/programs/office/onenote [Accessed on 26th September 2019] 
[3] Jeschke, S., Knipping, L., Natho, N., Schröder, C. \& Zorn, E. (2009) Information management in education using Tablet PCs and OneNote. ResearchGate. Available at:

https://www.researchgate.net/publication/228553998_Information_management_in_education_ using_Tablet_PCs_and_OneNote [Accessed on 26th September 2019]

[4] Microsoft 365 Blog. Top 10 things you didn't know about OneNote. Available at:

https://www.microsoft.com/en-us/microsoft-365/blog/2013/11/12/top-10-things-you-didnt-knowabout-onenote/ [Accessed on $26^{\text {th }}$ September 2019]

[5] Turner, J. (2011) Using Microsoft OneNote for Collaborative Vocabulary Notebooks in the Academic English Classroom. Available at: https://pdfs.semanticscholar.org/beff/ed7a470eb669967ea8590976b7fb5099aebd.pdf [Accessed on 26h September 2019]

[6] Guerrero, S., Dujardin, G., Cabrere-Andrade, A., Paz-y-Miño, C., Indacochea, A., Inglésferrándiz, M., Nadimpalli, H.P., Collu, N., Dublanche, Y., De Mingo, I. \& Camargo, D. (2016) Analysis and Implementation of an Electronic Laboratory Notebook in a Biomedical Research Institute. PLoS One 11(8). Available at:

https://journals.plos.org/plosone/article?id=10.1371/journal.pone.0160428 [Accessed on 26th September 2018]

[7] Tofan, D.C. (2010) Using a Tablet PC and OneNote 2007 To Teach Chemistry. Journal of Chemical Education Vol 87, No 1 pp47-48.

[8] Falconer, J.L., Nicodemus, G.D., Medlin, J.W., deGrazia, J. \& McDanel, K.P. (2014) a Thermodynamics Course Package in OneNote. ChE classroom Vol. 48, No. 4 Fall 2014.

[9] Shaw, K., Holmes, K., Preston, G., Smith, M., \& Bourke, S. (2014) Innovative teaching and learning. Part two: Spotlight on innovative practice. Scan 33(3)

[10] Mock, K. (2004) Teaching with Tablet PCs. Journal of Computing Sciences in Colleges 20 (2) pp17-27

[11] Evangelinos, G. (2014) An Electronic Personal Development Portfolio (ePDP) USING Microsoft OneNote. Networks Issue 17, January 2014, pp3-9

[12] McCullouch, B. (2010) A paperless, all digital engineering design class. In International conference on computing in civil and building engineering, edited by W. Tizani. Nottingham University Press, Nottingham

[13] Wenger, E. (2011) Communities of practice: A brief introduction. University of Oregon. Available at: https://scholarsbank.uoregon.edu/xmlui/handle/1794/11736 [Accessed on 26th September 2019]

[14] Brown, H., \& Ciuffetelli, D.C. (Eds) (2009) Foundational methods: Understanding teaching and learning. Pearson Education, Toronto.

[15] Smoker, T.J., Murphy, C.E. \& Rockwell, A.K. (2009) Comparing Memory for Handwriting versus Typing. Proceedings of the Human Factors and Ergonomics Society $53^{\text {rd }}$ Annual Meeting pp1744-1747.

[16] Vincent, J. (2016) Students' use of paper and pen versus digital media in university environments for writing and reading - a cross-cultural exploration. Journal of Print Media and Media Technology Research, 5 (2) pp97-106

[17] Mangen, A., Anda, L.G., Oxborough, G.H. \& Brønnick, K. (2015) Handwriting versus Keyboard Writing: Effect on Word Recall. Journal of Writing Research October 2015, pp299-319

[18] Cohen, L., Manion, L. and Morrison, K. (2000). Research Methods in Education. RoutledgeFalmer, London, UK. 